\title{
WHEN ROMAN ANTIQUITY AND RENAISSANCE CAME TOGETHER IN VIRTUAL 3D ENVIRONMENT: 3D MODELLING CONSIDERATIONS
}

\author{
M. Koehl ${ }^{1, *}$, M. Fuchs ${ }^{2}$, T. Nivola ${ }^{1}$, J. Koch ${ }^{2}$, L. Cartier ${ }^{1}$, S. Soussoko ${ }^{3}$ \\ ${ }^{1}$ INSA Strasbourg / ICube UMR 7357 - Engineering science, computer science and imaging laboratory - Remote Sensing, \\ Radiometry and Optical Imagery Group - mathieu.koehl@insa-strasbourg.fr, thibaut.nivola@ gmail.com, l.cartier@ttge.fr \\ 2 Archéologie Alsace - matthieu.fuchs@archeologie.alsace, jacky.koch@archeologie.alsace \\ ${ }^{3}$ Laetoli Production - samba@daba.fr
}

\section{Commission IV/9}

KEY WORDS: 3D modelling, reconstitution, archaeology, model optimization, AR/VR, knowledge based reconstruction.

\section{ABSTRACT:}

This paper is a review of the modelling of two edifices located in a city which developed on the vestiges of a Roman city during antiquity endowed in the 4th century with a military camp. The term castellum is used for the first structure. A second structure concerns the remains of a castle dismantled at the end of the 17th century, which was generally known only by an engraving in perspective made shortly before its demolition, and the cadastral matrix that had preserved the traces of its right-of-way. It is a Renaissance castle built in the $16^{\text {th }}$ century by the Württemberg family in the northeast corner of the ruins of the castellum. The projects contain a first part of data analysis and interpretation based on available documents. Similar sites close in terms of architecture, geographical location and construction period were also visited to get inspiration from them and to be able to make proposals for restitution. Despite the lack of data available, the multidisciplinary aspect of these projects is very important. In fact, the experience of archaeologists and the monitoring of modelling throughout its progress is essential to work out models that are both justifiable, at the level of the proposals made and sufficiently complete to be able to be highlighted. Once the models validated, they are integrated in a virtual way into the contemporary urban environment, through an interactive virtual tour. This paper reviews the principles implemented during the modelling, the rendering and the valorisation of the models thru virtual tours and AR/VR implementation.

\section{INTRODUCTION}

Restitution and 3D reconstruction are quite common concepts and especially in archaeology they are used for several decades. However, the development of digital tools has made it possible to take decisive steps forward, specifically with regard to the reliability and realism of restitution. These realistic models are then used as a medium of knowledge, for interactive, and now more and more virtual or augmented reality presentation. The main scientific objective of these models is the visualization, the comparison and the transposition of hypotheses into geometrically consistent numerical models. Restitution works have long time been limited to $2 \mathrm{D}$ renderings, but are now based on 3D digital techniques. The remains of two notable constructions, i.e. an antique castellum and a renaissance castle were thus identified and analysed for the conservation and preservation of the local heritage.

The main goal is therefore to render these buildings in $3 \mathrm{D}$ and to make them accessible in a virtual way. The general workflow can be summarized in Figure 1. Modelling is a progressive work. Preliminary research work must be undertaken, the available elements are put in relation in order to be able to make one or more restitution proposals. In this type of project, backtracking on modelling is unavoidable and essential in order to work out a final model whose modelling of each element can be justified.

The first objective of these modelling is to create an archaeological synthesis tool, the modelling logic being different according to the type of rendering desired. A second objective is to deliver models that will be easily usable or editable afterwards. Thus, the models created must be easily exportable, compatible with multiple platforms and optimized for real-time rendering and managing.

This project is aimed primarily at the general public. The modelling should therefore make it possible to enhance the site by exploring and interacting with elements, but must be carried out in a spirit of archaeological and scientific restitution. The advantage of a 3D model, in addition to making state for the general public, is to help the archaeologist to visualize a model as the hypotheses evolve. The digital model can thus be used as an archaeological synthesis tool, allowing to identify and differentiate what is known from what is not. Since the models are based on a combination of precise elements and more hypothetical reconstructions, it is important to make a clear distinction between the two.

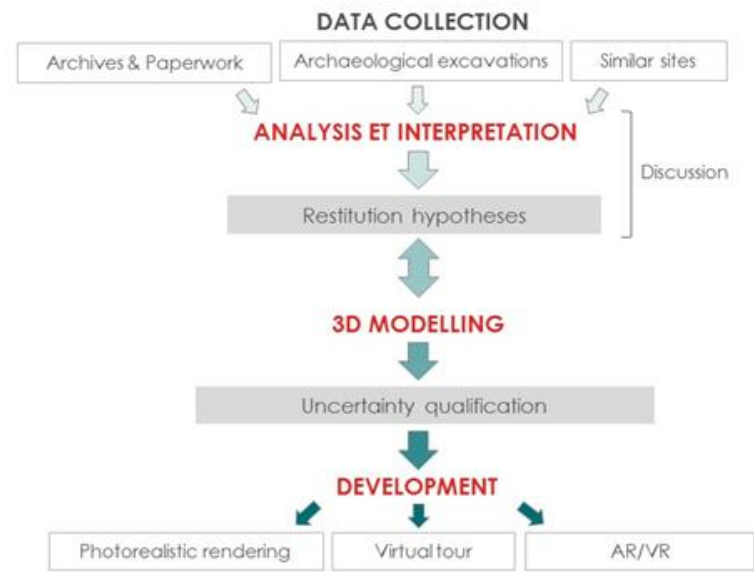

Figure 1. General project workflow

This paper reviews the principles implemented during the modelling beginning with the 'white' models. Multiple software packages were used to model the buildings, mainly Trimble SketchUp pro and Autodesk Maya. These software have their own specificities and are particularly contrasting in the 3D modelling principles. This paper also reviews these concepts and develops the methods used to lighten and optimize the model thus improving the performance of the rendering, especially in real time to offer an interactive tour, with the addition of augmented

* Corresponding author 
reality content. If 3D modelling is a subject that focuses a lot on the visual, the project proposes and implements interactive solutions of valorisation, accessible for the general public.

Finally, the paper covers the complete workflow from data interpretation, through 3D modelling and model optimization up to implementation in AR/VR environment and virtual tours.

\section{CONTEXT}

2.1 The Gallo-Roman Castellum and the Württemberg Castle of Horbourg-Wihr. Context and perspective of two historical fortifications.

The city of Horbourg-Wihr is located in the Alsace plain (FR), about $15 \mathrm{~km}$ west of the Rhine, $70 \mathrm{~km}$ south of Strasbourg. The city is crossed by a river, the Ill, which flows in the South-North direction. This geographical position is very important because it was decisive in choosing the location of the fortifications described, but also as an explanation of the state of conservation of the remains. From Gallo-Roman antiquity to modern times, Horbourg is located on a crossways of terrestrial and fluvial communication axes. The river Ill becomes widely navigable from Horbourg to Strasbourg. This configuration forms a commercial waterway used both in ancient and medieval times. For the East-West axis, Horbourg is located on the line that connects to the East the crossing of the Rhine and towards the West, once the Ill crossed, the opening towards the valley of Munster, as well as the access to the Col du Bonhomme, allowing a passage of the Vosges Mountain. Starting from these two cardinal axes, fluvial and terrestrial, a network of tracks was developed during Antiquity, giving birth to a flourishing GalloRoman city from the 1 st to the 3rd century whose capital was next to Basel (CH), in Augusta Raurica. Subsequently, during the 4th century, the regular incursions led to a fortification of the border on the Rhine with the construction of a series of towers, forts and castellum which constituted support points between the large legionary camps (castrum). The Roman army chose at that time (around 350-370 AD) Horbourg to host a powerful fort (castellum) that formed the military lock of central Alsace and supported the defenses that were in the first line on the Rhine. After the end of the Roman Empire in this region at the beginning of the 5th century, the site of Horbourg hosted an Alaman population, and gradually became the seat of an important seigneury during the Middle Ages. A first castle was built among the ruins of the Roman castellum. At the beginning of the 14th century, the counts of Württemberg bought the seigneury (1328) and made it the seat of their possessions in Alsace.

It was from the Renaissance that the Counts of Württemberg built a new castle better suited to the expectations of comfort and prestige for a princely court. In 1543, Count George I of Württemberg began work and the new castle was built on the northeast corner of the ancient Roman castellum. In 1597-98 new expansion works were undertaken by the duke Frederick who commended this beautification to the architect Heinrich Schickhardt. The castle, damaged by the Thirty Years' War, was dismantled by order of the King of France Louis XIV in 1675. He then lost his defensive role and the ramparts served as a stone quarry. Although still inhabited in the 18th century, the last buildings were sold as "National Good" during the French Revolution and were razed to recover all the materials. The castle really disappeared during the early 19th century. The cadastral matrix has preserved the memory of the boundaries of these two fortifications and remains legible on the maps from the Napoleonic cadaster of 1806, to the current cadaster. Three factors were therefore decisive for the project. First, a society of archaeology and local history was founded in 1991 (ARCHIHW, 1991), organizing research and publishing its results to make the archaeological heritage known to the population. A second determining factor was reinforced with the development of preventive archaeology at the beginning of the 21 st century. The public institution Archéologie Alsace carried out the vast majority of excavations on the territory of the city, becoming an essential actor for the scientific knowledge of the site. Finally, as third key factor, after decades of disinterest, knowledge of the past has become a city policy issue for the new municipality elected in 2014. It is the conjunction of these different factors and wills that allowed the emergence of the idea to revive two key monuments disappeared from the heritage of the city. A partnership has been set up between the history association, the city, Archéologie Alsace and INSA Strasbourg to develop the 3D modelling of the Gallo-Roman castellum and the Württemberg castle. Located in the center of actual city and partially geographically overlaid despite twelve centuries that separated their respective edifices, it appeared that the most relevant way to restore them was to organize the digital modelling. From the historical documentation gathered the project could clearly highlight the scientifically attested parts and the parts that were reconstructed in comparison with other similar buildings. For archaeologists, this work made it possible to interrogate all the accumulated data in a new way and to check its consistency and propose a new interpretation. For topographical engineering students, the project was a challenge to mobilize disparate geographical and architectural data, ensure topographical accuracy and develop models in a totally renewed urban environment. For the municipality, the project makes it possible to offer its fellow citizens an unprecedented visualization of important but disappeared remains and an appropriation by modern, accessible, educational and very attractive media.

\subsection{The castellum: origin and description}

The first records of discoveries date back to the 16th century, when the castle of the counts of Württemberg, which occupied the northeast corner of the Late Roman fortification, was enlarged. The humanist Beatus Rhenanus related in 1543 the discovery of ancient vestiges. In 1597-1598, the Württemberg architect Heinrich Schickardt explicitly evoked the remains of an ancient fortification when he renovated the castle, but did not provide any description of these remains. It was not until the 1820 s that relevant remarks were proposed about the dating and probable organization of the castellum by Philippe Aimé de Golbéry, author of the first monograph of the site. Finally, excavations were undertaken jointly by Emile-Alphonse Herrenschneider, then pastor at Horbourg, and the architect of historic monuments Charles Winkler between 1853 and 1888 . This work made it possible to uncover two corner towers, four intermediate towers and the south gate, and from this, to restore a precise map of the enclosure - a map that still serves as a reference at the present time (Figure 2). Since the end of the 19th century, there have been few occasions to make field works. In 1971-1972, a survey on about $60 \mathrm{~m}^{2}$ was carried out on the edge of the eastern wall of the castellum. A series of programmed surveys conducted by Matthieu Fuchs and the local archaeology association recognized new sections in 1996, 2004, 2010, 2018 and 2019. Finally, the development of preventive archaeology in the old center allowed François Schneikert to make clarifications at the base of the foundations of the northern front in 2017. The castellum forms an almost regular quadrilateral with external dimensions of $174.50 \mathrm{~m} \times 167 \mathrm{~m}$, an area of $2.9 \mathrm{ha}$, and internal dimensions of $168.50 \mathrm{~m} \times 167 \mathrm{~m}$, an internal area of $2,7 \mathrm{ha}$. This is the most important fortification of late antiquity located on the left bank between Castrum Rauracense/Kaiseraugst (approx. 3.5 ha) to the south and Argentorate/Strasbourg (nearly 20 ha) to the 
north. Having been the object of many destruction and reuse of its materials, no portion is more visible in the present city.

The theoretical map, almost square, has 4 circular corner towers, 8 intermediate harrow-shaped towers, and 4 doors flanked by two rectangular towers each. Were actually observed: 3 corner towers on 4,6 intermediate towers on 8 , and 2 of the 8 towers flanking the doors. Clues allow to propose the hypothesis of a flatbottomed ditch surrounding the castellum and constituting an advanced defense. The corner towers reach $6 \mathrm{~m}$ in diameter. The intermediate towers, 6-7 $\mathrm{m}$ wide, form a semi-circular projection of $3 \mathrm{~m}$ on the outside and a rectangular projection of $2 \mathrm{~m}$ on the inside of the curtain wall, itself $3 \mathrm{~m}$ thick. There are two types of doors, each flanked by two rectangular towers. Those of the north and the south have a simple passage of $3 \mathrm{~m}$ wide for a total depth of about ten meters. The west, and probably the east, has a double pass. The height of the curtain wall had to reach at least $6 \mathrm{~m}$ at the round road and $8 \mathrm{~m}$ at the top of the crenellation, the height of the towers is estimated at $12 \mathrm{~m}$. The internal layout of the fortification has barely been documented, the most part is urbanized today. A portion of track seems to have been observed behind the south gate at the end of the 19th century, as the map of the architect $\mathrm{Ch}$. Winkler mentions a pavement $8 \mathrm{~m}$ wide located in the axis of the passage of the door. In the center, at the intersection of the two lanes connecting the doors was observed a building that E.-A. Herrenschneider had mistakenly interpreted as the praetorium of a military camp. However, the renewal of the excavation of this building in 2004 made it possible to demonstrate that it is a temple built at the end of the $2 \mathrm{nd} /$ beginning of the 3rd century and therefore contemporary of the civil agglomeration. The building obviously persisted through the occupation phase of the 4th century and beyond. No building specific to the camp itself is therefore recognized within the fortified quadrangle. In the past, the dating of the construction of the castellum was most often proposed by typological analogy with fortifications of similar shape and size, in particular with those of Alzey (D) and Bad Kreuznach (D).
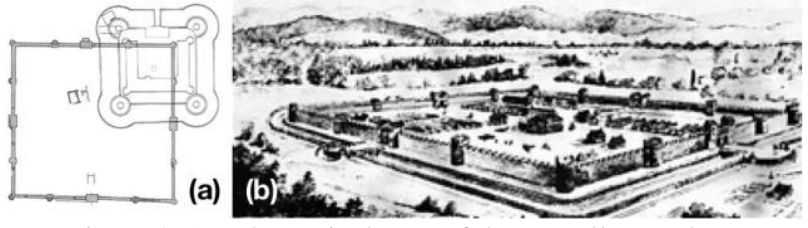

Figure 2. (a) Theoretical map of the castellum and

Württemberg castle - E.A. Herrenschneider (1894); (b)

Elevation of the castellum - C. Winkler (1905)

\subsection{The Württemberg castle: origin and description}

Several significant events in the course of history have made it possible to find written traces mentioning the existence of the Württemberg castle since the 10th century. Thus, it is today possible to reconstruct the great phases of this castle over the centuries. Several centuries after the construction of the castellum, in the Middle Ages, the sires of Horbourg were the head of a powerful seigneury. The family's fortune resided mainly in its castle installed on the ruins of the castellum as well as on the revenues of the tolls that result from their location conveniently located on the road crossing the plain of the Rhine from west to east. The castle was destroyed at the end of the 12th century and sold 2 centuries later with all its seigneury as well as that of Riquewihr by the brothers Walter IV and Burckard II of Horbourg to their relative, Count Ulrich of Württemberg. The Horbourg family died in 1374. Count Georges of Württemberg, Sire of Riquewihr, undertook in 1543 to rebuild the castle as well as new defensive works. At the end of the 16th century he decided to enlarge this new castle by extending the central body of the seigneurial home by the construction of 2 wings. This redevelopment was assigned to the architect Heinrich Schickhardt who told in his writings that the "castle is not only a fortress, but a quite pleasant place of stay for a prince". The existence of the castle was brief but eventful. Indeed, its reconstruction was completed in 1603 but it subsequently entered the tumult of the Thirty Years' War begun in 1618. During this war the castle was bombed and occupied by the Swedes, followed by an epidemic of plague that forced the inhabitants of Horbourg to find refuge in Colmar for about fifteen years. It was not until 1648, at the signing of the Treaties of Westphalia, that the castle was restored by Louis XIV to Georges II who lived there until 1662.

From that date, the castle was occupied by the French and its condition deteriorated continuously over time. His dismemberment was ordered in 1675 . The castle then ended up serving as a quarry. Today there are only few visible traces of the castle. There is only a part of the ditch and a part of the counterscarp wall along the Rue des Écoles.

\section{THE MODELLING}

\subsection{The modelling of the castellum}

The virtual model of castellum was made from the different types of data presented above, and from architectural hypotheses. As the data available are incomplete, they do not allow the buildings to be described in detail and in a homogeneous manner. To model these buildings in three dimensions, it was therefore essential to rely on the knowledge of archaeologists. Trimble SketchUp was chosen as modelling software. SketchUp is indeed interesting for 3D modelling, the GUI is intuitive and the range of basic tools coupled with many plugins makes it possible to create precise models. In addition, the combination with rendering software Lumion makes it possible to obtain very good quality results. The modelling stage is initiated by the representation of the main volumes of the building, which leads to a restitution of what is called the "white model" (Figures 3).

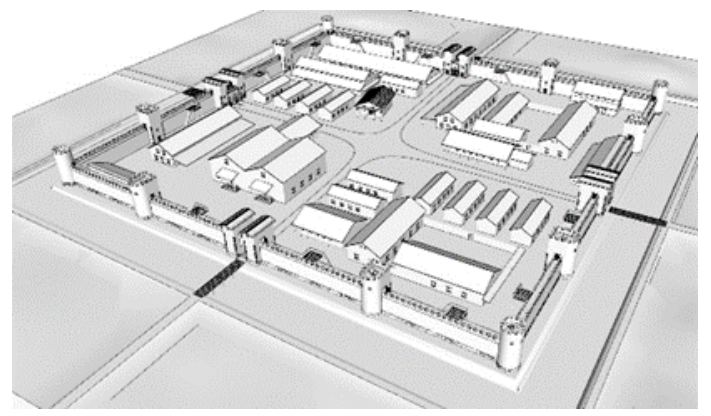

Figure 3a. 'White' model of the castellum

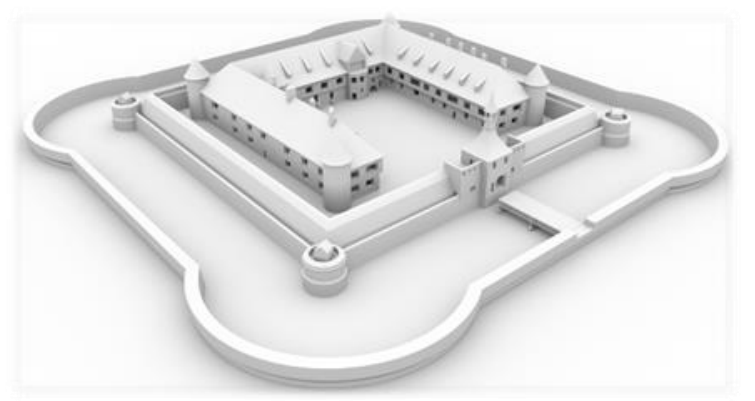

Figure 3b. 'White' model of the castle 
This is very useful and makes it possible to give a homogeneous and smoothed representation of the level of detail and the level of information. A finer modelling is then carried out gradually, with the representation of the details elements. To model a site, it is preferable to start from a map. For the castellum, the theoretical map was therefore imported and scaled. After obtaining the base shape of the site by digitization of the map, a 'Push/Pull' tool allows to extrude a surface in a volume. Overall, modelling involves drawing surfaces and subsurfaces and go gradually into detail. Sketchup has some drawbacks especially when using rounded surfaces. Indeed, as in all modelling software the curves are actually polylines. The user must define the number of sides corresponding to the degree of detail to approximate the circle by a polygon. The higher the number of segments, the smoother the surface geometry. Conversely, the lower the number of segments and the more polygonal the geometry of the object. When creating a circular object it is very important to take this parameter into account for two reasons: (i) by creating a volume from the circular surface, it will be impossible to modify this parameter. It would therefore be problematic to have to re-model an object entirely because of its too polygonal aspect, (ii) the file weight is directly affected by the number of segments. It is therefore very important to think about the best compromise when creating a rounded surface, between the detailed visual aspect and the weight management of the file.

Among the tools used during this modelling, we can remember: (i) the 'Follow-me' tool which allows you to extrude a profile along a guideline curve, (ii) the 'Adapt a photo' tool which allows you to model in $3 \mathrm{D}$ from a $2 \mathrm{D}$ image, properly redefine the drawing axes of the image.

Among the important plugins we can evoke Curviloft dedicated to the generation of surfaces from contours and composed of three distinct tools: (i) 'Loft by Spline' allowing to create one surface joining two separate surfaces, (ii) 'Loft along Path' to join two surfaces following the path given by a curve, (iii) 'Skinning' to create a mesh by creating areas bounded by closed contours that do not need to be in the same plane. CLF Shape Bender is another plugin used for creating complex surfaces, in particular, for bending a straight component along a curve. It has been useful for duplicating components such as doors or windows on round angular towers. (Figure 4)
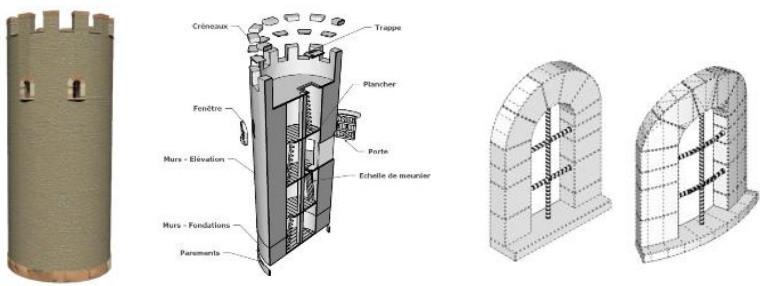

Figure 4. Round towers and windows

\subsection{Model validation}

The modelling work is progressive. Each restitution proposal requires a preliminary research work. Backtracking on modelling is inevitable and essential in order to work out a final model whose modelling of each element can be justified. Still in this restitution process, the different choices were justified by modelling sheets (Figure 5). The modelling method was done independently for each important element of the model (towers, ramparts, entrances, etc.). Once these parts were validated, they were assembled to obtain a final thorough model. Working independently on each part brings three advantages: (i) not working on a single model and being able to keep the different phases of evolution of a piece, by versioning the model, (ii) be able to model in a more fluid environment because of a fewer number of objects, (iii) simplify the visualization of the component structure.
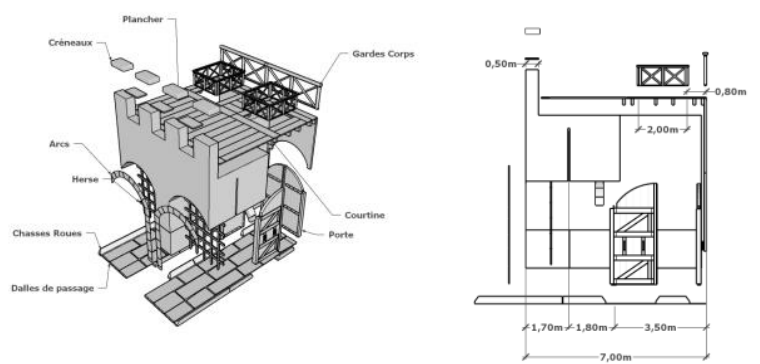

Figure 5. Extract of modelling sheet: entrance of castellum.

\subsection{Organizing the model by components and layers}

One of the most important functions of the Sketchup software is the component tool. Indeed, to properly structure the 3D model, it must be developed into components. Several advantages are linked to this structure: (i) the creation of a component makes it possible to define an entity, whose geometry is independent of the rest of the model, (ii) duplicated components retain a link to the original component (as an instance). Any modification applied to an instance of a component, will then be applied to all other instances that can be repeated. On the opposite, an instance may be dissociated from the others by transforming it into a single component. In addition, it is possible to establish a hierarchy of main components (towers, entrances, ramparts, etc.) themselves composed of secondary components (windows, floor, doors, etc.).

Another structure uses layers. When a component is placed in a disabled layer, all constitutive elements of the component are disabled, regardless of the sub-components it contains and the layers assigned to them.

One of the objectives of the virtual model is to be organized and to be visualized in a spirit of archaeological synthesis and transparency regarding the degree of uncertainty. The use of layers allowed us to visualize the uncertainty of the elements by a color-coded view. To do this, the idea of Dell'Unto's (2013) layer-based organization responds well to the problems of our subject. Thus, of the six levels of certainty proposed, only four, more adapted to the data we have at our disposal, have been implemented (Landes et al., 2019). In addition to these layers concerning the level of certainty, three additional layers allow a more or less detailed model display (Figure 6). This was done for viewing and display purposes, depending on the type of information displayed on the model.

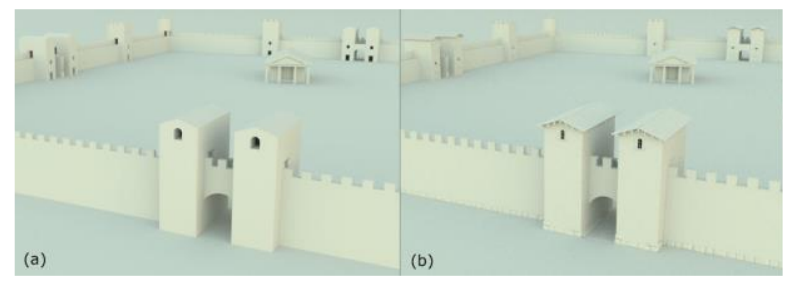

Figure 6. Overview of LOD - Visualization of castellum structure (a); Detailed visualization of castellum (b).

It is also possible to add attributes to the different components, to associate general informative fields such as: (i) a brief description, (ii) some information about its main dimensions, (iii) the location, (iv) a score of 3 distinguishing: (1) the uncertain elements, (2) the elements presumed according to the theoretical 
map, (3) the elements of excavated areas, (v) a link to a detailed sheet explaining the modelling method and the sources used based on the idea presented by Dufay (2012).

These fact sheets summarize in a 3-page digest: (i) a description of the component, (ii) the presentation of the data which enabled the modelling of the component and its origin, (iii) an exploded view of the component and the various sub-components, (iv) the main dimensions of the building, (v) a part explaining the interpretation that was made with the archaeologists, (vi) a part concerning the modelling of the component, which presents in detail the different dimensioning applied using sections and elevation views (Figure 3), (vii) a color-coded view of the component based on the four levels of uncertainty, (viii) a summary table of the sub-components, including their degree of uncertainty.

\subsection{The modelling of the Württemberg castle}

The creation of a 3D model with Sketchup software is rather simple. Many plugins can be added to perform more advanced operations. However, through this project we were able to approach some of the limitations of the software, leading us to evolve towards Autodesk Maya (2018). The major difficulty encountered lies in the geometries of the 3D objects created with Sketchup. Indeed, the software automates many tasks and in particular the decomposition of polygons into triangles (Figure 7), making the geometry of objects difficult to modify afterwards.
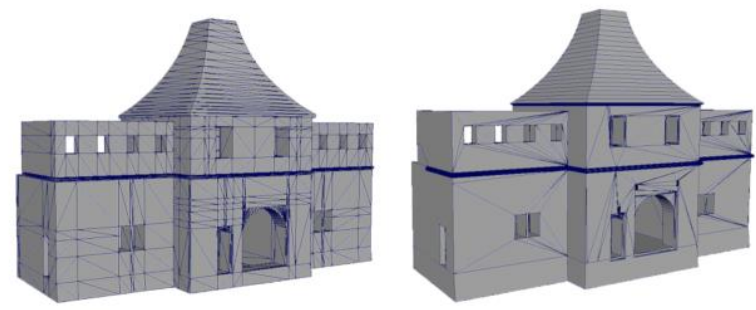

Figure 7: Decomposition of the simplified entrance of the castle (left into quads Maya, right into triangles SketchUp).

Little visibility is given during this step, which can lead to problems later, especially when applying textures or when importing the model into a rendering engine. On the other hand, Maya allows to master each stage of construction and to perfectly manage the geometry of its 3D objects. It also makes it possible to simplify the model by applying optimization methods, thus improving the performance of the rendering, especially in real time. Finally, Maya produces very clean renderings, which makes it a good choice for the production of realistic models. On the other hand, Maya allows to master each stage of construction and to perfectly manage the geometry of its 3D objects. Maya is a polygonal modelling software just like Blender, $3 d$ s Max and many more. Polygonal modelling consists of building 3D objects from the 3 components of a polygon: the faces, the edges and the vertices. The different combinations of operations on these components (extrusion, rotation, scaling, cutting, etc.) will lead to the final 3D model. Maya allows to model from primitive polygonal surfaces (sphere, cylinder, cube, etc.) which serve as the basis for the construction of 3D objects or from NURBS 2 which are tools facilitating the obtaining of particular smooth shapes by generalization of Bézier curves. These are called curves in Maya and serve as guides for the creation of NURBS surfaces. Editing points in a curve automatically changes the created NURBS surface. Once these surfaces are created, they can then be converted into polygons so that they can be reworked more easily.

\subsection{Model optimization}

The creation of a virtual environment requires careful reflection before even starting 3D object modelling, otherwise the desired rendering cannot be achieved. In choosing to carry out such a project, the creator must bear in mind that the more objects the scene is composed, the heavier the model will be and the more difficult it will be to propose a rendering in real time. Optimization techniques applied to each object created are a guarantee of success for the rest of the project. Surand (2019) reviews the key points to focus on to optimize a 3D model. At first he focused to the number of polygons constituting an object (polycount). Every 3D object is composed of polygons that differ from each other by their number of sides. We have the triangles ( 3 sides), the quads (4 sides) and the Ngons (5 sides and more). Modelling is usually done from quads, which are more suitable for the construction of 3D objects. A real-time rendering engine will then convert all polygonal faces into triangles. The more polygons an object has, the longer it will take to load. To avoid overloading the scene, Surand (2019) advises to classify the objects in the 3D scene into 3 categories and to assign to each one a maximum number of polygons: (i) the main objects that the user will particularly look at, (ii) the intermediate objects slightly distant or less important, (iii) distant objects such as decorative elements very far from the center of the scene.

Reducing the number of polygons is not a sufficient technique in itself to optimize an entire 3D model. The textures applied to these polygons can actually cause the rendering performance to drop if they are not pre-processed. The resolution of the images must depend on the 3 categories mentioned above: an object of high importance will be applied a large texture size and vice versa. It often happens that we need to realize a very detailed object and therefore require a very large number of polygons. To optimize, a solution consists of making two versions of this type of object: one in low resolution called LowPoly and one in high resolution called HighPoly. The LowPoly model has a small number of polygons and is intended to be imported into the realtime rendering engine. The HighPoly model takes up the basics of the previous model by adding all the necessary details. The idea is then to transfer the visual details of the HighPoly model into the texture of the LowPoly object (Webster, N. L., 2017). Each object in the scene must be designed to possess the smallest number of faces. It is therefore necessary to think of removing from the object the invisible faces at the sight of the visitor as often those below the objects, for example. The number of faces must be sufficient to accentuate the realism of the scene but also must not exceed a certain threshold in order not to limit the performance of the rendering.

\subsection{Texturing}

Adding an image to a 3D object is sometimes not enough to make it realistic. Indeed, a multitude of details such as grain, hollows, bumps, transparency or other constituents of a material cannot be correctly transcribed by simply applying a $2 \mathrm{D}$ image on the surface of the object. To avoid modelling these small details, one solution is to superimpose on our image special texture maps that allow to add a certain amount of information to the material when rendering. The first map is used for almost all 3D models. This is the diffusion map (diffuse map) that gives the color or texture of the object. We can add the specular map, which indicates which parts of the model should shine. It is represented by a grayscale image and is used especially for surfaces where the brightness is not uniform. 
The photorealism of a model is given in part through the use of maps highlighting the bumps and depressions of the surface. Three types of maps exist today: bump, normal and displacement maps. Bump maps are grayscale images that create an illusion of depth. The darker the pixels in the image, the greater the depth impression. The normal maps use RGB information corresponding to the $\mathrm{X}, \mathrm{Y}$ and $\mathrm{Z}$ axes in $3 \mathrm{D}$ space. This information describes the orientation of the normals, indicating the shadow areas to be displayed at rendering. This type of maps is often used on animated objects. Finally, the movement maps physically move the mesh of the surfaces on which they are applied. These ones, however, result in additional computation time to the rendering, due to the creation of this new geometry. We can also use maps of roughness, transparency or reflection. Many software allow to create most of these maps, such as Materialize, Substance Bitmap2material or Awesome bump which is a free alternative to Crazy Bump. Once the modelling has been largely completed and validated by archaeologists, we can now texturing the model, which greatly contributes to its realistic aspect. However, before any application of textures on the polygons of the scene, it is necessary to carefully prepare the UVs of the 3D objects. UVs are one of Maya's assets. These are 2D coordinates of textures linked to the vertices of the polygons of the 3D scene. They help to associate the pixels of the image used for texture with the mesh surface of 3D objects. UVs define the areas on which the texture is applied.

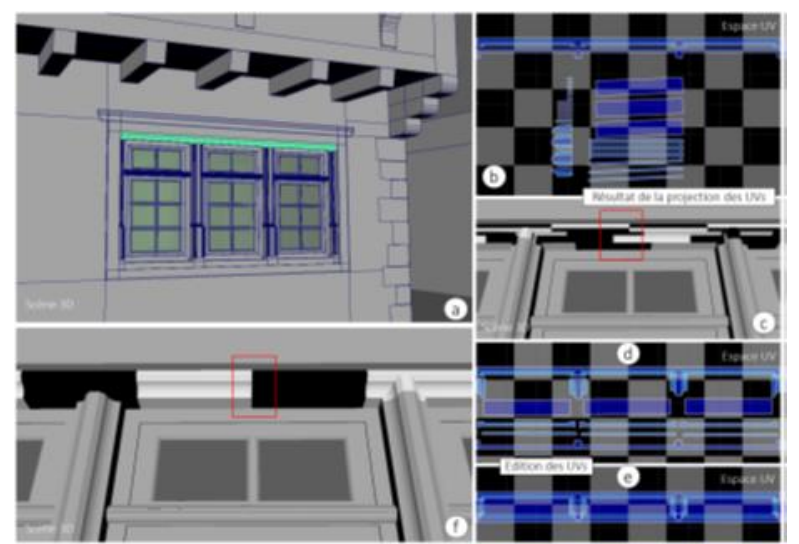

Figure 8: Detail of modelling and texture management

Two main components allow to work in the UV editor: edges and UV coordinates. Editing texture mapping on $3 \mathrm{D}$ objects is done through them and through numerous alignment, cutting, scaling and many other tools, until the desired result is achieved (Figure 8).

This analysis could be supplemented by the use of lighting tools and modelling of the immediate and distant environment of the sites.

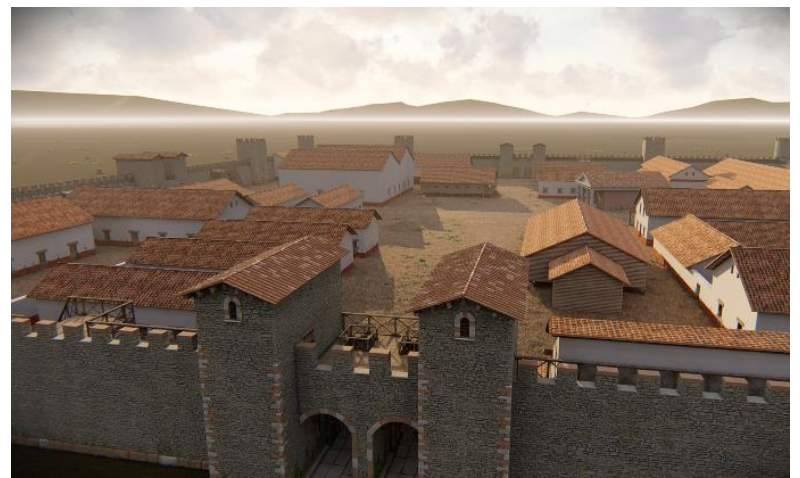

Figure 9a : Model of castellum (SketchUp)

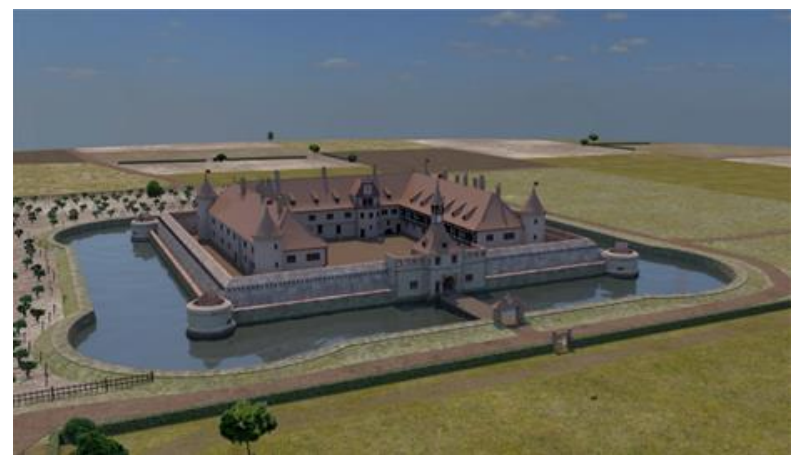

Figure 9b: Model of Württemberg Castle (Maya)

Figures 9 illustrate the models carried out under Sketchup (castellum) and Maya (Württemberg Castle).

\section{VALUATION OF MODELLING}

\subsection{Virtual tours}

A virtual tour (Koehl and Brigand, 2012 - Koehl et al., 2013) consists of $360^{\circ}$ panoramas in which the visitor can move virtually. The content of these visits can be documented by adding images or texts, providing the visitor with additional information useful to his understanding.

A first virtual tour was made by Nivola, Th. (2018) integrating the castellum. It allows to walk virtually in the city of Horbourg through 3 types of panoramas presented Figure 10 (a-c). The virtual tour allows you to navigate between different points of view and to easily change the environment to make the castellum appear at its exact antique location. The objective was then to reuse the same virtual tour by modifying it to add several views of the Württemberg castle. This step provide an application making cohabit the castellum with the castle (Cartier, L. 2019) (Figure 10 (d-e)). In the same way, it would be possible in the future to continue to complete the tour in order to cover all the remarkable places of the documented city.

\subsection{Castle insertion into the contemporary environment}

As for the castellum, the new virtual tour contains mixed panoramas that mixes the contemporary with medieval view in a same panoramic image. The goal of this approach is to allow visitors to rely on current urban landmarks to better understand where the castle once was located. For a qualitative integration of the $3 \mathrm{D}$ model of the castle in the selected panoramas, it is necessary to extract the visual renderings of the building from the appropriate positions. These locations are then integrated into the modelling environment under Maya, before following pipeline proposed by Nivola, Th. (2018). Rendering in Maya requires the creation of a specific camera placed horizontally at a height of $1.75 \mathrm{~m}$ at the GNNS positions of the panoramic views. The projection of this camera is configured to obtain a spherical panorama, which is completed with the information relating to the image acquisition (focal length, horizontal and vertical field of view values).

The models are accessible online via the Sketchfab platform, which hosted the models on the web portals of the scientific partner and the city information system. This platform is low cost solutions to visualize the model in virtual reality thanks to a smartphone and a Google Cardboard or to a more efficient VR headset. Virtual tours have been used to document historic buildings for several years. It is an interactive way to discover a site and learn more about its history through the integration of 
documentation, texts, archive images or videos into the virtual tour.

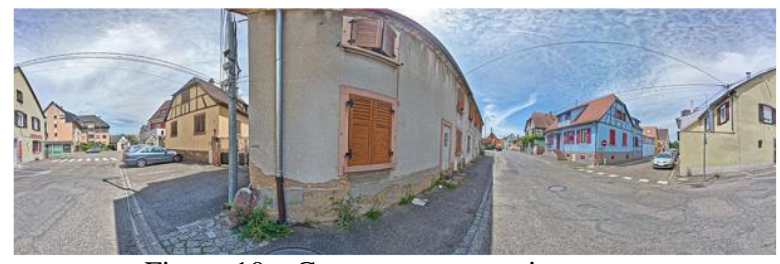

Figure 10a. Contemporary environment.

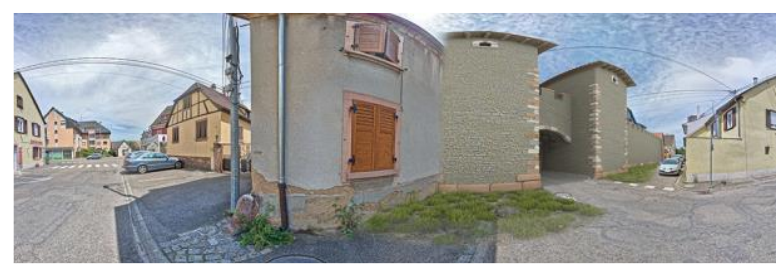

Figure 10b. Castellum in contemporary environment.

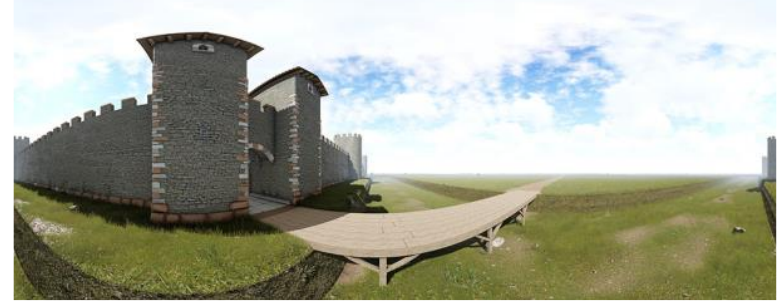

Figure 10c. Castellum in historic environment ( $4^{\text {th }}$ century)

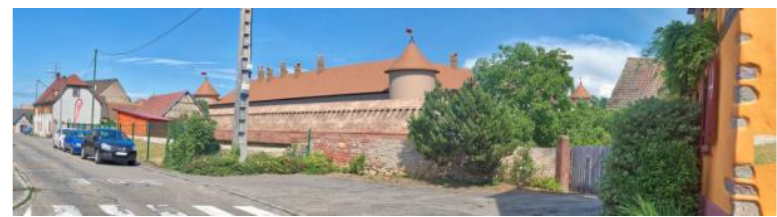

Figure 10d. Castle insertion - Extract of panoramic view (Rue des Écoles)

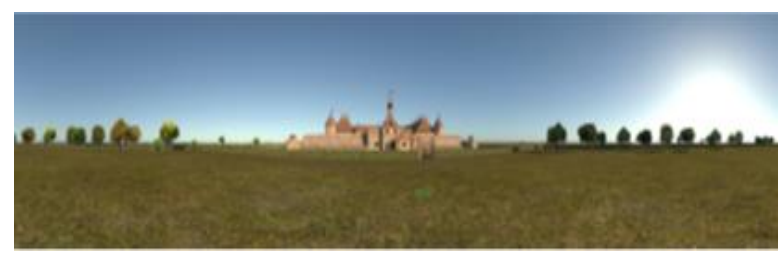

Figure 10e. Castle in historic environment.

This tour makes it possible to walk virtually in the city through a dozen points of view and to navigate between the different time periods in order to analyse the castellum and the castle located at original place. The proposed virtual tour will therefore be based on fixed panoramic photos, on which will be integrated photorealistic renderings of the model, in order to present the building in the current urban environment. The second solution consists in the use of augmented reality (AR), which allows to add to user's perception a layer of contextual information. This technology is sometimes preferred to virtual reality (VR) (Figure 11) for this project because it does not separate the user from the contemporary environment and provides him with useful urban landmarks for his understanding.

\subsection{Augmented reality}

The city of Horbourg-Wihr wishes to set up in the coming years a tourist tour built around its outstanding historic monuments.
Some of them are no longer visible at the moment, such as the castellum or the Württemberg castle, so the objective is to choose the right technology to make them reappearing virtually. Two main solutions exist: (i) virtual reality and (ii) augmented reality. Augmented reality was finally selected for this project for different reasons. The visit must be accessible to all and must be easy to use. An app installed directly on a tablet or downloadable from a smartphone is a solution everyone can use. The development of an augmented reality application has been tested from the SDKs that appear most suitable for our purpose. But the position indicated by the GNSS sensor of a smartphone is too inaccurate (between 5 to $10 \mathrm{~m}$ ) to be used as a reference to position the model. The stability of the model would then have been compromised. This technology still needs to be explored further.

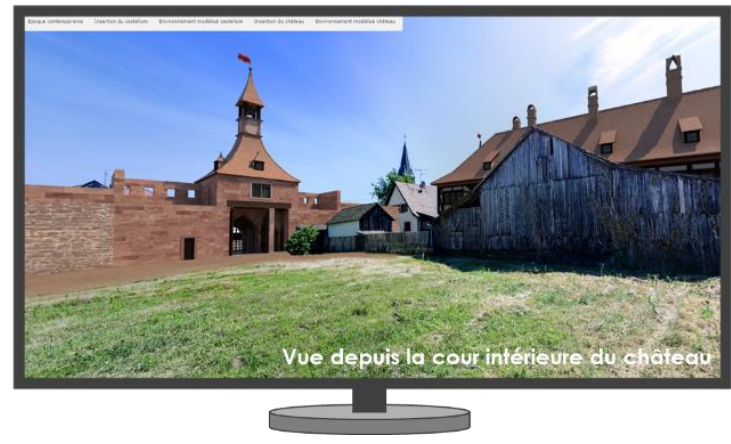

Figure 11. Screenshot of VR immersion in the model of castle

\section{CONCLUSION}

These projects have made it possible to set up methodologies for the reconstruction of the antique castellum and the Württemberg castle in Horbourg-Wihr. An interpretative process to reach conclusions on the orientations, positions and geometries of the different elements of the two models has been used. These steps were carried out based on the insertion of data from archaeological excavations but also, when these were no longer sufficient, by comparison with similar sites in terms of geometry and period. The castellum was modelled under SketchUp, while the castle was subsequently modelled using the Maya software, the main technical characteristics of which were discussed. Once the 'white models' were completed, we prepared all the 3D UVs so that the textures would be perfectly applied to them. Important work has been done on the rendering of materials to render the final models. The 3D models were also worked on with the aim of optimizing, using as few faces as possible in the construction of each object or creating background entirely based on textures, thus avoiding modelling a multitude of details.

For transparency regarding the realization of 3D models and in order to distinguish the proven facts from the uncertain ones, color-coded models have been created according to 4 levels of uncertainty. Explaining sheets have been created for each of the main components of the models that make it possible to synthesize all the data and reasoning used for their reconstitution. Once a 3D model is generated, the question of its diffusion becomes essential. We therefore have created a virtual tour integrating the panoramas relating to the observation of the castellum and the castle. We have included on the one hand the views of the antique or medieval period and on the other hand the panoramas of the models integrated into the contemporary urban frame. 


\section{PERSPECTIVES}

The possible prospects for the continuation and improvement of this project are as following: (i) the digital model of the Württemberg castle could be enriched by the reconstruction of the interiors of the east wing of the house focused on the research and conclusions made throughout this project, (ii) the framework structure of the castle having already been modeled (Koehl et al., 2013), we can now imagine integrating it into the digital model of the castle created with Maya. The modelling of the seigneurial farms located on the outskirts of the castle would also be a possibility to accentuate the realism of the model.

The virtual tour composed of the castellum and the castle can easily be completed by other remarkable buildings of the city of Horbourg-Wihr. A full tour could be set up.

Finally, a draft application of augmented reality could be developed during this project. It can be used as references in order to continue in this direction. The development of a pointby-point application to meet the set specifications would likely require extensive functionality and customized technical support.

\section{ACKNOWLEDGMENTS}

We thank the municipality of Horbourg-Wihr for the support of these projects.

\section{REFERENCES}

ARCHIHW, 1991. https://archihw.org/

S. Boeykens, C. Himpe, and B. Martens. A Case Study of Using BIM in Historical Reconstruction. The Vinohrady Synagogue in Prague. Digital Physicality | Physical Digitality, 1 (November 2014): pp. 729-738, 2012. doi : 10.13140/2.1.2997.0721. https://lirias.kuleuven.be/handle/123456789/350340.

Cartier, L. (2019). Modélisation 3D du château disparu des Wurtemberg à Horbourg-Wihr et exploitation de la réalité augmentée pour une mise en valeur dans la trame urbaine contemporaine. Master Thesis - INSA Strasbourg, 104 pages.

Cartier, L (2020). Modélisation 3D du château disparu des Wurtemberg à Horbourg-Wihr et exploitation de la réalité augmentée pour une mise en valeur dans la trame urbaine contemporaine. $\mathrm{XYZ} \mathrm{n}^{\circ} 162,1^{\mathrm{er}}$ trimestre 2020 , pp. 63-68. ISSN 0290-9057.

Dell'Unto, N., Leander, A., Dellepiane, M., Callieri, M., Ferdani, D., and Lindgren, S. (2013). Digital reconstruction and visualization in archaeology: Case-study drawn from the work of the Swedish Pompeii project. In: 2013 Digital Heritage International Congress, vol. 1, pp. 621-628. IEEE.

Fanini, B. and Pagano, A. (2015). Interface design for serious game visual strategies the case study of "imago bononiae". In: 2015 Digital Heritage, vol. 2, pp. 623-626.

Farella, E., Menna, F., Nocerino, E., Morabito, D., Remondino, F., and Campi, M. (2016). Knowledge and valorization of historical sites through 3D documentation and modeling. In: Int. Arch. Photogramm. Remote Sens. Spatial Inf. Sci., XLI-B5, 255262, doi: 10.5194/isprs-archives-XLI-B5-255-2016.

Houde, S., Bonde, S., and Laidlaw, D. H. (2015). An evaluation of three methods for visualizing uncertainty in architecture and archaeology. In: 2015 IEEE Scientific Visualization Conference (SciVis), pp. 149-150. IEEE.
Kersten, T. P., Tschirschwitz, F., Deggim, S. and Lindstaedt, M. (2018). Step into Virtual Reality - Visiting Past Monuments in Video Sequences and as Immersive Experiences. MDPI Books, pp. 192-219. doi: 10.3390/books978-3-03842-685-1.

Koehl, M. and N. Brigand, N. (2012). Combination of Virtual Tours, 3D Model and Digital Data in a 3D Archaeological Knowledge and Information System. In: ISPRS - Int. Arch. Photogramm. Remote Sens. and Spatial Inf. Sci., pp. 439-444, 2012. doi: 10.5194/isprsarchives-XXXIX-B4-439-2012.

Koehl, M., Schneider, A., Fritsch, E., Fritsch, F., Rachedi, A. and Guillemin, S., (2013). Documentation of historical building via virtual tour: the complex building of baths in Strasbourg. In: ISPRS Arch., vol. XL-5/W2, TC V, XXIV. pp. 385-390.

Koehl, M. Viale, A., and Reeb, S. (2013). A historical timber frame model for diagnosis and documentation before building restoration. In: Int. Annals Photogramm. Remote Sens. Spatial Inf. Sci., II-2/W1, pp. 201-212, 2013

Landes, T., Heissler, M., Koehl, M., Benazzi, T. and Nivola, T. (2019). Uncertainty visualization approaches for 3D models of castles restituted from archeological knowledge. In: Int. Arch. Photogramm. Remote Sens. Spatial Inf. Sci., XLII-2/W9, 409416, doi: 10.5194/isprs-archives-XLII-2-W9-409-2019.

Menna, F., Nocerino, E., Remondino, F., Dellepiane, M., Callieri, M., and Scopigno, R. (2016). 3D digitization of an heritage masterpiece - a critical analysis on quality assessment. In: Int. Arch. Photogramm. Remote Sens. Spatial Inf. Sci., vol. XLI-B5, pp. 675-683. doi:10.5194/isprsarchives-XLI-B5-675201.

Mortara, M. and Catalano, C. (2018). 3D virtual environments as effective learning contexts for cultural heritage. In: Italian Journal of Educational Technology, 26(2): pages 5-21. ISSN 2532-4632 e-ISSN 2532-4632.

Nivola, Th (2018). Modélisation 3D du Castellum de HorbourgWihr et exploitation de la réalité augmentée pour une mise en valeur dans la trame urbaine contemporaine. Master thesis INSA Strasbourg, 89 pages, 2018.

Surand, Th. (2019). Optimisation de modèles 3D dans le cadre d'une utilisation pour simulateurs en temps réel. 18 pages. hal02110683.

Thomson, J., Hetzler, E., MacEachren, A., Gahegan, M., and Pavel, M. (2005). A typology for visualizing uncertainty. In: Visualization and Data Analysis 2005, volume 5669, pp. 146158. International Society for Optics and Photonics.

Tscheu, F. and Buhalis, D. (2016). Augmented reality at cultural heritage sites. In: Information and communication technologies in tourism 2016, pp. 607-619. Springer.

Webster, N. L. (2017). HighPoly to LowPoly workflows for realtime rendering. In: Journal of visual communication in medicine, 40(1): pp. 40-47. doi:10.1080/17453054.2017.13136 